\title{
A Simulation Study on the Swelling and Shrinking Behaviors of Nanosized Montmorillonite Based on Monte Carlo and Molecular Dynamics
}

\author{
Kaiwen Tong, ${ }^{1,2}$ Jianhua Guo, ${ }^{1,2}$ Shanxiong Chen, ${ }^{1}$ Fei Yu $\mathbb{D},{ }^{1}$ Shichang $\mathrm{Li},{ }^{1,2}$ \\ and Zhangjun Dai $\mathbb{1}^{1}$ \\ ${ }^{1}$ State Key Laboratory of Geomechanics and Geotechnical Engineering, Institute of Rock and Soil Mechanics, Chinese Academy \\ of Sciences, Wuhan 430071, China \\ ${ }^{2}$ University of Chinese Academy of Sciences, Beijing 100049, China
}

Correspondence should be addressed to Zhangjun Dai; zjdai@whrsm.ac.cn

Received 12 July 2021; Accepted 20 August 2021; Published 15 September 2021

Academic Editor: Yu Wang

Copyright (C) 2021 Kaiwen Tong et al. This is an open access article distributed under the Creative Commons Attribution License, which permits unrestricted use, distribution, and reproduction in any medium, provided the original work is properly cited.

\begin{abstract}
Montmorillonite is the main mineral source for the swelling and shrinking of expansive soils. The macroscopic phenomena of soil are affected by the action of deep-level nanosized minerals. In order to illustrate the nanoscale mechanism from the molecular level, a combination of Monte Carlo and molecular dynamics was used to explore the swelling and shrinking characteristics of montmorillonite. The results showed that the basal spacing, free swelling ratio, and void ratio were positively correlated with water content but were inversely proportional to the change of CEC. The hysteresis phenomena of swelling and shrinking were the most significant at a water content of $40 \%$. Compared with the expansive soil, the nanoscale shrinkage curve of montmorillonite also included three stages of normal shrinkage, residual shrinkage, and no shrinkage. The relative concentration of water molecules conveyed information such as the thickness and position of the hydration film and explained the difference in swelling and shrinking caused by the above variables. The changes in the number and length of hydrogen bonds revealed the order of formation and the process of destruction of hydrogen bonds during the reaction. The similarity of the trends between the basal spacing, binding energy, and the number of hydrogen bonds indicated that the swelling and shrinking of the crystal layer are a reflection of the molecular interaction, and the hydrogen bonding is particularly critical.
\end{abstract}

\section{Introduction}

Expansive soil is widely distributed worldwide and generally exists on the surface of the earth. It is mainly composed of clay minerals such as montmorillonite, illite, and kaolinite [1]. Due to its engineering characteristics of swelling and shrinking, it often causes damage to roadbeds, slopes, and buildings, bringing huge losses to the economic security of countries around the world $[2,3]$.

Both natural and remodeled expansive soils have extremely complex mineral compositions and random structures. The research scale ranges from nanosized minerals to macroscale clays, and there are complex interactions between particles, as well as between particles and electrolyte solution [4-7]. So far, the explanation of the swelling and shrinking mechanism of expansive soil has not been unified. Most of them are based on the macrolevel, ignoring the coupling process of physics, mechanics, and chemistry on the microscale [8-10]. Studies have shown that montmorillonite plays an important role in the swelling and shrinking of expansive soil. Starting with nanolevel minerals is a prerequisite to fully understand and clarify its deformation and destruction [11]. However, it is highly difficult to test the interaction between the solid and liquid molecules of crystal layer by experimental methods, which hinders the further development of clay mineralogy to a certain extent.

With the improvement of molecular simulation technology, many scholars have achieved remarkable results in the behaviors of montmorillonite and the influencing factors of swelling. Boek et al. [12] first used the Monte Carlo method to simulate the hydrated phenomena of $\mathrm{Na}$-montmorillonite 
and found the basic spacing increased with the rise of water content. Marry et al. [13] obtained its structure and kinetic features to calculate the diffusion coefficient of water molecules and interlayer cations. In order to determine the key factors affecting the swelling properties, Chang et al. [14] investigated the hydrated behaviors under the action of different cations such as $\mathrm{Li}^{+}, \mathrm{Na}^{+}$, and $\mathrm{K}^{+}$by molecular simulation. Furthermore, Wang and Zeng [15] regarded the water content and the types of interlayer cations as variables, sorting the ability of $\mathrm{Li}^{+}, \mathrm{Na}^{+}$, and $\mathrm{K}^{+}$to organize oxygen atoms through the radial distribution function. Katti et al. [16] relied on Fourier transform infrared and molecular dynamics to study the swelling behaviors of $\mathrm{Na}$-montmorillonite in various organic fluids. Abduljauwad et al. [17] considered the influence of dry density on swell potential and pressure of $\mathrm{Na}$ montmorillonite from the perspective of cohesive energy density (CED). In addition to its own conditions, Li [18] reported the changes in the interlayer structure of Na-montmorillonite and Cs-montmorillonite in the range of $300 \mathrm{~K}-600 \mathrm{~K}$. But up to date, there are few evaluations on the influence of cation exchange capacity (CEC), and most of the above researches are obviously insufficient in system and depth. Recently, studies involving the shrinking of montmorillonite after losing water have rarely been mentioned. In addition, the range of water content that the existing literature focused on is too narrow $(0 \sim 30 \%)$. It cannot reflect the characteristics of montmorillonite in the entire stage of swelling and shrinking and lacking a connection with macroscopic experimental phenomena [19-21].

In this paper, based on the molecular dynamics, the influence of water content, types of interlayer cations, and cation exchange capacity on the swelling and shrinking behaviors of montmorillonite under normal temperature and pressure was explored. The simulation results of the nanoscale were utilized to figure out the microscopic mechanism and preliminarily explained the macroscopic experimental phenomena.

\section{Methodology}

\subsection{Swelling Behaviors of Montmorillonite}

2.1.1. Model Construction. The Wyoming montmorillonite (Mnt) selected in this article has been widely studied by scholars $[22,23]$. The unit cell belongs to the monoclinic system, space group $\mathrm{C} 2 / \mathrm{m}$ with $\alpha=\gamma=90^{\circ}, \beta=99^{\circ}, a \approx 5.23 \AA$, and $b \approx 9.06 \AA$. When montmorillonite is in a completely dry state, $c \approx 9.60 \AA$. While adsorbing one, two, three, and four layers of water molecules, the $c$ values are $12.5 \AA, 15.5 \AA$, $18.5 \AA$, and $21.5 \AA$, respectively [21]. To keep the number of particles in the system constant and eliminate the boundary effect of the model, referring to the experience of Skipper [24], the simulation cell consisted of 8 unit cells $(4 \times 2 \times 1$ array of clay unit cell) using periodic boundary conditions and the space group in the simulated environment is P1. Considering the complicated forms and time-consuming calculation in the MCY and TIP4P, the SPC/E model was selected to better reflect the properties of water and describe the interaction between water and clay $[23,25]$. By adjusting the bond angle $\mathrm{H}-\mathrm{O}-\mathrm{H}$ and bond length $\mathrm{H}-\mathrm{O}$ to $109.47^{\circ}$ and $1 \AA$, respectively, the dipole moment of the water molecule will be close to the real value [21]. The nanoscale Mnt and the macroscopic samples were bridged through water content, fully reflecting the whole stage of swelling and further establishing the connection between two scales. The initial water content (the percentage of the mass of water molecules to the mass of clay, namely, $\left.m_{\mathrm{H} 2 \mathrm{O}} / m_{\text {clay }} \times 100 \%\right), c$ value, and number of hydrated layers under different numbers of water molecules are listed in Table 1.

According to Lowenstein's nonadjacent principle [26] followed by multiple isomorphous replacement of montmorillonite, $\mathrm{Si}^{4+}$ in tetrahedral sheet and $\mathrm{Al}^{3+}$ in octahedral sheet will be replaced by $\mathrm{Al}^{3+}$ and $\mathrm{Mg}^{2+}$, respectively. Take Na-Mnt or Ca-Mnt with a layer charge of 0.75 ( 0.38 per half unit cell) as an example; there are six $\mathrm{Na}^{+}$or three $\mathrm{Ca}^{2+}$ between the layers, and the molecular formula is $\mathrm{Na}_{0.75}\left\{\mathrm{Si}_{7.75} \mathrm{Al}_{0.25}\right\}\left[\mathrm{Al}_{3.5} \mathrm{Mg}_{0.5}\right] \mathrm{O}_{20}(\mathrm{OH})_{4} \cdot \mathrm{nH}_{2} \mathrm{O}$ or $\mathrm{Ca}_{0.375}\left\{\mathrm{Si}_{7.75} \mathrm{Al}_{0.25}\right\}\left[\mathrm{Al}_{3.5} \mathrm{Mg}_{0.5}\right] \mathrm{O}_{20}(\mathrm{OH})_{4} \cdot \mathrm{nH}_{2} \mathrm{O}$. The supercell configuration of $\mathrm{Na}-\mathrm{Mnt}$ with $0 \sim 4$ hydrated layers is depicted in Figure 1.

2.1.2. Simulation Design. Layer charge density and cation exchange capacity (CEC) are important criteria for the classification of clay minerals. In soil science, CEC means the milligram equivalent of cation exchange per $100 \mathrm{~g}$ of soil, namely, the molar charge per unit mass of soil. Layer charge and CEC can be transformed into each other, but a previous work has rarely linked the two indicators. To this end, this paper constructed three types of Mnt models according to the standard "geological exploration instruction of bentonite deposit" GB 12518-1990, including low-level charge type (0.20 0.35 per half unit cell), transition type (0.35 0.45 per half unit cell), and high-level charge type ( $0.45 \sim 0.60$ per half unit cell). The transition from layer charge to CEC (eq/g) is realized by formula (1), so as to be related to the CEC detected by macroscopic experimental methods.

$$
\operatorname{CEC}(\mathrm{eq} / \mathrm{g})=1000 \times \frac{2 \sigma / e^{\prime}}{\mathrm{FW} / 100}
$$

where $\sigma$ is the layer charges, $e^{\prime}$ is the charge of an electron, FW (g) represents the mass of the model. Equation (1) presents that the CEC of the mineral is affected by the volume, natural density, and layer charge of the model, and the CEC of Mnt is various under different water contents [27]. Tables 2 and 3 list the variable gradients of water content and layer charge density. The water content range of 16 232 water molecules corresponds to water content in the range of $5 \% \sim 70 \%$, covering all states of the soil when it expands and shrinks [28]. In view of the fact that the interlayer cations of Mnt are mostly $\mathrm{Na}^{+}$and $\mathrm{Ca}^{2+}$ under actual conditions and the layer charge density generally varies from 0.20 to 0.60 per half unit cell, so the total number of groups simulated is 66 , corresponding to $66 \mathrm{CEC}$ values. The CEC of Mnt is not greatly affected by the types of cations (Tables 2 and 3). According to the changes of CEC, it can be roughly divided 
TABLE 1: The parameters of Mnt with different numbers of water molecules between layers.

\begin{tabular}{|c|c|c|c|c|c|c|c|c|c|c|c|}
\hline \multirow{2}{*}{ Parameters } & \multicolumn{11}{|c|}{ The number of water molecules } \\
\hline & 16 & 32 & 64 & 96 & 128 & 149 & 166 & 183 & 199 & 216 & 232 \\
\hline The number of hydrated layers & 1 & 1 & 1 & 2 & 3 & 3 & 3 & 3 & 3 & 4 & 4 \\
\hline Initial $c$ value $(\AA)$ & 12.5 & 12.5 & 12.5 & 15.5 & 18.5 & 18.5 & 18.5 & 18.5 & 18.5 & 21.5 & 21.5 \\
\hline Initial water content (\%) & 5 & 10 & 20 & 30 & 40 & 45 & 50 & 55 & 60 & 65 & 70 \\
\hline
\end{tabular}

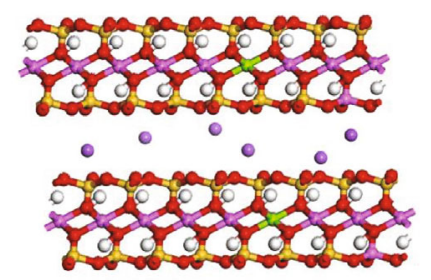

(a)

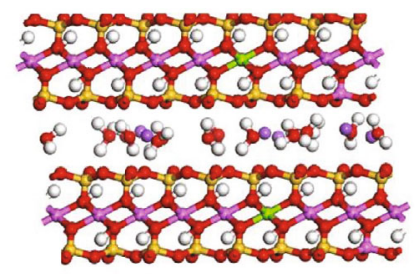

(b)

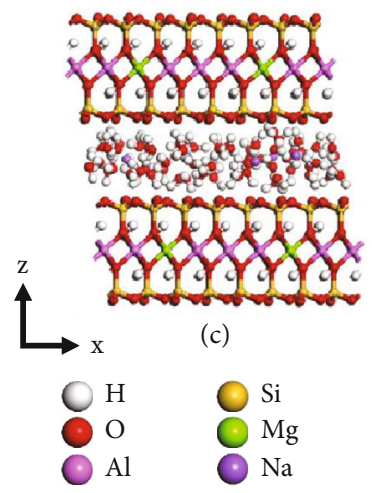

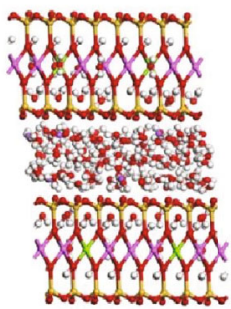

(d)

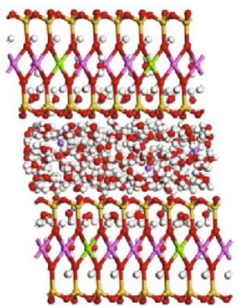

(e)

hydrated.

TABle 2: CEC of Na-Mnt.

\begin{tabular}{|c|c|c|c|c|c|c|c|c|c|c|c|c|c|}
\hline \multirow{2}{*}{ Layer charge density (per half unit cell) } & \multirow{2}{*}{ Type of layer charge } & \multirow{2}{*}{ Number of $\mathrm{Na}^{+}$} & \multicolumn{11}{|c|}{ Water content $(\%)$} \\
\hline & & & 5 & 10 & 20 & 30 & 40 & 45 & 50 & 55 & 60 & 65 & 70 \\
\hline 0.20 & Low-level & 3 & 49 & 47 & 43 & 40 & 37 & 35 & 34 & 33 & 32 & 31 & 30 \\
\hline 0.38 & Transition & 6 & 97 & 93 & 85 & 79 & 73 & 70 & 68 & 65 & 63 & 61 & 60 \\
\hline 0.60 & High-level & 10 & 160 & 153 & 140 & 130 & 121 & 119 & 112 & 108 & 105 & 101 & 99 \\
\hline
\end{tabular}

TABle 3: CEC of Ca-Mnt.

\begin{tabular}{|c|c|c|c|c|c|c|c|c|c|c|c|c|c|}
\hline \multirow{2}{*}{ Layer charge density (per half unit cell) } & \multirow{2}{*}{ Type of layer charge } & \multirow{2}{*}{ Number of $\mathrm{Ca}^{2+}$} & \multicolumn{11}{|c|}{ Water content $(\%)$} \\
\hline & & & 5 & 10 & 20 & 30 & 40 & 45 & 50 & 55 & 60 & 65 & 70 \\
\hline 0.25 & Low-level & 2 & 65 & 62 & 57 & 53 & 49 & 49 & 45 & 44 & 42 & 41 & 40 \\
\hline 0.38 & Transition & 3 & 97 & 93 & 85 & 79 & 73 & 70 & 68 & 65 & 63 & 61 & 60 \\
\hline 0.60 & High-level & 5 & 160 & 153 & 141 & 130 & 121 & 116 & 112 & 108 & 103 & 102 & 99 \\
\hline
\end{tabular}

into three levels, namely, LCEC (30 60 eq/g), MCEC $(60 \sim 100 \mathrm{eq} / \mathrm{g})$, and HCEC (100 160 eq/g).

2.1.3. Computational Parameters and Procedure. The simulation was performed by Materials studio software package on the system containing Mnt, water, and ions. The force field, CLAYFF, proposed by Cygan et al. [29] was applied to describe the process of molecular dynamics. With reference to the parameters of previous experience $[15,21]$, the long-range Coulomb electrostatic force was processed by the Ewald summation method with an accuracy of $10^{-}$ ${ }^{4} \mathrm{kcal} / \mathrm{mol}$. The van der Waals force of the short-range interaction was acquired by the atom-based method, and the cutoff distance, spline width, and buffer distance were set to 
$12 \AA, 0.5 \AA$, and $0.5 \AA$, respectively. The basic steps included the adsorption of water molecules and interlayer cations, geometric optimization, structural relaxation, and the kinetic simulation of swelling. The specific details are as follows:

(1) The adsorption of water molecules and interlayer cations: in accordance with the gradients of the layer charge, the isomorphous replacement was accomplished first, and then, the initial model was constructed. The corrected water molecules and $\mathrm{Na}$ or $\mathrm{Ca}$ were given the corresponding charges through CLAYFF force field, and specific parameters are listed in Table 4 [30]. Sorption of water molecules and interlayer cation $\left(\mathrm{Na}^{+}\right.$or $\left.\mathrm{Ca}^{2+}\right)$ was carried out using the Metropolis Monte Carlo method in the Sorption module of the software. Specifically, the parameters selected for ratios of "exchange," "conformer", "rotate," "translate," and "regrow" are 0.39, 0.2, 0.2, 0.2 , and 0.2 , respectively [9]. In this way, initial crystal structures after adsorption were built.

(2) Geometric optimization: to gain the conformation with the lowest potential energy, the energy of adsorbed Mnt was minimized by the Smart algorithm. The convergence tolerance and displacement were controlled to $1.0 e-4 \mathrm{kcal} / \mathrm{mol}$ and $5.0 e-5 \AA$, respectively, and the maximum number of iteration steps was 5000. When the energy of the system dropped to a stable level and reached the convergence criterion, the optimized configuration was chosen to lay the foundation for the next step.

(3) Structural relaxation: the model was further optimized globally to prevent the energy of the system from falling into the local optimum in the NVT ensemble, and a more stable configuration can be generated. In this section, the kinetic simulation of $\mathrm{Na}-\mathrm{Mnt}$ and Ca-Mnt was carried out at $25^{\circ} \mathrm{C}$ ( $298 \mathrm{~K})$. The temperature was controlled by the more efficient Velocity Scale method with an allowable error of $5.0 \mathrm{~K}$. Considering that most models have reached equilibrium at the $50^{\text {th }} \mathrm{ps}$, the total simulation time and time step were, respectively, $200 \mathrm{ps}$ and $0.5 \mathrm{fs}$ to improve accuracy [30].

(4) The kinetic simulation of swelling: when simulating the swelling of Mnt in the NPT ensemble, all the atomic degrees of freedom need to be released to apply a fixed temperature $(298.15 \mathrm{~K})$ and pressure (1 atm). Since Mnt is an inorganic crystal and its structure and shape are known, the pressure can be fixed by the Berendsen method. To save simulation time and increase accuracy, this research integrated previous experience and set the total simulation time to $200 \mathrm{ps}$ $[30,31]$. The time step was conducted for $0.1 \mathrm{fs}$.

Using the method of Chang et al. [14] for reference, the new basic spacing of hydrated clay minerals after swelling was taken as the initial basal spacing for the following simulation. The trajectory of the balanced model will be extracted and processed by Perl script.

2.2. Shrinking Characteristics of Montmorillonite. When the mineral undergoes swelling reaction, the water molecules in the pores of the soil will evaporate with the influence of temperature, leading to water content of soil decreasing and further shrinking under external force. If the water content is less than a certain critical value, the volume of the soil will no longer change. This study concentrated on the shrinking process of Mnt with atmospheric pressure after evaporation. For the Monte Carlo method, firstly, it can provide more detailed information without providing experimental data and calculate a reliable and balanced system by determining the energy, pressure, and temperature of the configuration. Secondly, this method can more realistically describe the water absorption and desorption of water molecules randomly distributed among the layers of clay particles to simulate the process of shrinking. Finally, the algorithm is less restricted by geometric conditions such as the size, number of atoms, and orientation of the system, which is convenient for obtaining more realistic and accurate simulated results $[23,32]$.

The fundamental difference between the swelling and shrinking of Mnt lies in the adsorption and desorption of water molecules. The current work was combined with the research of Zheng et al. [23] and desorbed a fixed amount of interlayer water molecules in the expanded model by Monte Carlo. During the shrinking period, the water content of the entire system changes from $70 \%$ to $0 \%$. It means that when the process of swelling is completed at a higher water content (such as $70 \%$ ), Monte Carlo will be used on this basis to make the system reach a lower water content (such as $65 \%$ ) as a model premise of simulating shrinking by deleting a specific number of water molecules.

The parameters are the same as those in Section 2.1. Geometry optimization, structural relaxation, and simulation of shrinking (NPT ensemble) were executed in sequence, and finally the trajectory data after equilibrium was sorted.

2.3. Data Analyses. Before the discussion and analysis of the results, it is necessary to figure out the way and physical meaning of certain nanolevel parameters. For instance, the basal spacing, free swelling ratio, and void ratio can display the phenomena of swelling and shrinking from different aspects, as well as the relative concentration, binding energy, number, and length of hydrogen bonds reflecting its reaction mechanism. The ergodic hypothesis points out that even if the system is in an equilibrium state, its configuration will dynamically change with time and the system will experience all possible microscopic states at this time. Therefore, it is statistically significant to extract the data of the stable configuration to calculate the following indicators.

2.3.1. Basal Spacing $\left(d_{001}\right.$-value). The change of the basal spacing represents the ability of swelling and shrinking of Mnt, including the thickness of solid minerals and interlayer spacing. The formula is defined as [21] 
TABLE 4: Force field and charges of montmorillonite and water.

\begin{tabular}{lccccc}
\hline Type & Atom & Symbol & $q(\mathrm{e})$ & $\sigma_{i j}(\AA)$ & $\varepsilon_{i j}(\mathrm{kcal} / \mathrm{mol} \cdot \AA)$ \\
\hline \multirow{4}{*}{ Montmorillonite } & O (bridging oxygen) & ob & -1.050 & 3.5532 & 0.1554 \\
& O (hydroxyl oxygen) & oh & -0.950 & 3.5532 & 0.1554 \\
& $\mathrm{Na}$ (interlayer cation) & $\mathrm{Na}$ & 1.0 & 2.6378 & 0.1301 \\
& $\mathrm{Ca}$ (interlayer cation) & $\mathrm{Ca}$ & 2.0 & 3.2237 & 0.1000 \\
& $\mathrm{H}$ (hydroxyl hydrogen) & ho & 0.425 & - & - \\
& $\mathrm{Mg}$ (octahedral magnesium) & $\mathrm{mgo}$ & 1.360 & 5.9090 & $9.0298 \times 10^{-7}$ \\
& $\mathrm{Al}$ (tetrahedral aluminum) & at & 1.5750 & 3.7064 & $1.8405 \times 10^{-6}$ \\
& $\mathrm{Al}$ (octahedral aluminum) & ao & 1.575 & 4.7943 & $1.3298 \times 10^{-6}$ \\
\multirow{2}{*}{ Water } & $\mathrm{Si}$ (tetrahedral silicon) & $\mathrm{st}$ & 2.100 & 3.7064 & $1.8405 \times 10^{-6}$ \\
\hline & $\mathrm{O}\left(\mathrm{H}_{2} \mathrm{O}\right)$ & $\mathrm{o}^{*}$ & -0.820 & 3.5532 & 0.1554 \\
& $\mathrm{H}\left(\mathrm{H}_{2} \mathrm{O}\right)$ & $\mathrm{h}^{*}$ & 0.410 & 0.0000 & 0.0000 \\
\hline
\end{tabular}

$$
d_{001} \text {-value }(\AA)=\frac{V}{a \times b \times \sin \alpha} \text {, }
$$

where $V\left(\mathrm{~cm}^{3}\right)$ is the statistical average volume in the system and $a(\AA), b(\AA)$, and $\sin \alpha$ are the average unit cell parameters.

2.3.2. Free Swelling Ratio (FS). Compared with the basal spacing, the free swelling rate is a professional measure of threedimensional swelling. The larger the free swelling ratio, the stronger the swelling abilities of the soil. It is defined macroscopically as the ratio of the difference between the volume of loose dried soil particles when freely accumulated in the air and water to the volume when freely accumulated in the air; thus, Ahmed and Abduljauwad [9] gave a way to describe the free swelling ratio (FS) of expansive clays on a microscale and the specific form is expressed as

$$
\mathrm{FS}(\%)=\frac{\mathrm{IDD}-\mathrm{FDD}}{\mathrm{FDD}} \times 100 \% \text {, }
$$

where $\operatorname{IDD}\left(\mathrm{g} / \mathrm{cm}^{3}\right)$ is the initial dry density and FDD $\left(\mathrm{g} / \mathrm{cm}^{3}\right)$ is the final dry density.

2.3.3. Void Ratio (e). The shrinking of soil is mostly characterized by the shrinkage curve (the relationship curve between void ratio and water content) [28]. According to the Connolly algorithm, the porosity of the clay matrix can be calculated by the hard-sphere test-particle insertion (TPI) method. The Connolly radius was $1.0 \AA$. The van der Waals scale factor and grid interval were 1.0 and $0.25 \AA$. Hereby, the free volume (FV) and occupied volume (OV) can be solved, and the void ratio is given as

$$
e=\frac{\mathrm{OV}}{\mathrm{FV}}
$$

where OV $\left(\AA^{3}\right)$ and $\mathrm{FV}\left(\AA^{3}\right)$, respectively, are the free volume (including the volume of water molecules) and the solid phase volume of clay after swelling.
2.3.4. Relative Concentration. Relative concentration refers to the ratio of the number of atoms or molecules on a certain plane of the model to the number of atoms or molecules in the entire system, quantitatively depicting the position and distribution of atoms or molecules. With this parameter, the process of swelling and shrinking of $\mathrm{Na}-\mathrm{Mnt}$ and $\mathrm{Ca}$ Mnt under different CEC can be further explored.

2.3.5. Binding Energy $\left(E_{\text {bind }}\right)$. Whitley and Smith [33] discovered that the main thermodynamic factor affecting the swelling of Mnt is the energy term in the free energy of swelling. To distinguish differences between the swelling and shrinking with different water content, types of cations, and CEC from the perspective of thermodynamics, the binding energy was introduced as [34]

$$
E_{\text {bind }}(\mathrm{kcal} / \mathrm{mol})=-E_{\text {inter }}=\left(E_{\text {solid }}+E_{\mathrm{H}_{2} \mathrm{O}}\right)-E_{\text {total }} \text {. }
$$

The binding energy $E_{\text {bind }}(\mathrm{kcal} / \mathrm{mol})$ in (5) is the negative value of the interaction energy $E_{\text {inter }}(\mathrm{kcal} / \mathrm{mol})$, which is used to measure the interaction energy between the solid and liquid phase and quantitatively characterize the interaction force between molecules. The more positive the binding energy, the stronger the attraction between the solid and liquid molecules. The greater the absolute value of the negative binding energy, the more significant the attraction between water molecules and the clay wafer. $E_{\text {solid }}(\mathrm{kcal} / \mathrm{mol}), E_{\mathrm{H}_{2} \mathrm{O}}(\mathrm{kcal} / \mathrm{mol})$, and $E_{\text {Total }}(\mathrm{kcal} / \mathrm{mol})$ are the energy of the solid phase, liquid phase, and the total energy of the system, respectively.

2.3.6. The Number and Length of Hydrogen Bonds. Hydrogen bonding is a special nonbonding interaction. For the force field, CLAYFF, it is reflected in the interaction between static electricity and van der Waals. It can be divided into intermolecular hydrogen bonds and intramolecular hydrogen bonds according to their types [35]. Relevant studies have shown [21] that intermolecular hydrogen bonds in Mnt are mainly formed between water molecules and bridging oxygen atoms on the surface of the wafer. On the one hand, the intermolecular hydrogen bonds are generated between the hydroxyl hydrogen 


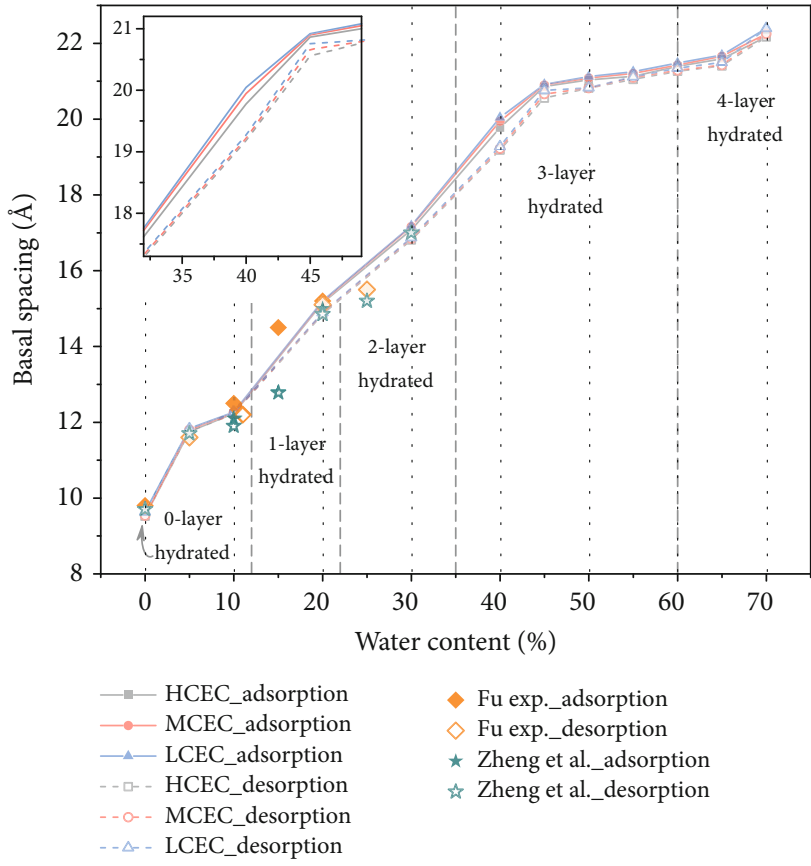

(a)

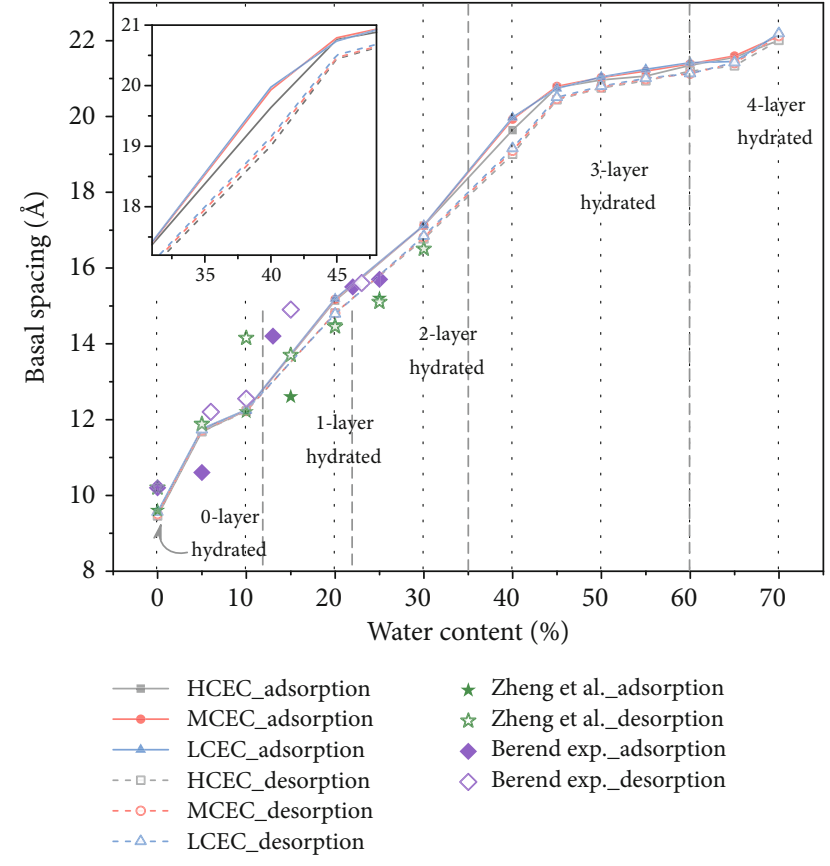

(b)

FIgURE 2: Hysteresis curve of Mnt during swelling and shrinking: (a) Na-Mnt and (b) Ca-Mnt.

in the structure and the common oxygen atoms of siliconoxygen tetrahedron and aluminum-oxygen octahedron and between a few bridging oxygen atoms. When water molecules are adsorbed into the crystal layer or desorbed from the interlayer, the hydrogen bonds will vary accordingly. Thus, the changes of hydrogen bonds in the system may be related to the swelling and shrinking behaviors of Mnt.

In view of this, we determined the order of formation during swelling, the process of destruction during shrinking, and the distribution of water molecules between layers by the number of hydrogen bonds $\left(N_{\mathrm{HB}}\right)$, the number of hydrogen bonds per water molecule $\left(N_{\mathrm{HB}, \mathrm{p}}\right)$, and the length of hydrogen bonds $\left(L_{\mathrm{HB}}\right)$. Using Perl script to define the bonding rule of hydrogen bonds is that the distance between the largest donor and acceptor was $2.5 \AA$, and the smallest angle between the donor, hydrogen atom, and acceptor was $90^{\circ}$ [21].

\section{Results and Discussion}

3.1. Hysteresis Curve of Swelling and Shrinking. Referring to (2), the relationships between $d_{001}$-value and water content of Na-Mnt and Ca-Mnt under different CEC are shown in Figures 2 (a) and 2(b). $d_{001}$-value has slightly decreased with the increase of CEC (Figure 2), which is consistent with the test results of Ahmed and Abduljauwad [9]. In the process of Mnt from swelling to shrinking, $d_{001}$-value has undergone four hydrated states. Generally, it first grew with the rise of water content and then declined with the decrease of water content. The swelling and shrinking had evident hysteresis effects. Tang [28] also found the irreversibility of the swellshrinking deformation of the sample in the macroscopic test. The experimental results of $\mathrm{Fu}$ [19] and Berend [20] using $\mathrm{X}$-ray diffraction (the range of water content is $0 \% \sim 30 \%$ ), and the simulation results of Zheng et al. [23] are in good agreement with the hysteresis curve in Figure 2, which largely confirms the accuracy of the simulation results in this work. Comparing the changes of $d_{001}$-value between $\mathrm{Na}$ Mnt and Ca-Mnt, the interlayer cations had an effect on the swelling and shrinking of Mnt. However, Na-Mnt only had a smaller swelling advantage than Ca-Mnt, which may be related to the hydrated capacity of cations [21].

As shown in Figures 2(a) and 2(b), similar to the hysteresis behaviors of hydrated Mnt under the influence of temperature [36], the swell-shrinking phenomenon was the most significant when the water content varied from $30 \%$ to $50 \%$. The difference in $d_{001}$-value between absorption and desorption of Mnt was the largest when the water content was around $40 \%$ (the partial enlarged view on the upper left side of Figure 2). By linking the macroscopic results, the corresponding critical water content is also about $40 \%$ when desiccation cracks are beginning to appear [27, 37]. The discovery suggested that the volumetric shrinkage of Mnt may create spatial conditions for the formation of cracks on expansive soils.

3.2. Swelling Properties of Montmorillonite. Figures 3(a) and 3(b) are the swelling curves of Na-Mnt and Ca-Mnt, where the dry state is considered the reference point for calculating FS. The changes of FS with water content under different CEC displayed that, similar to $d_{001}$ - value, FS of Mnt presented an upward trend with the increase of water content as a whole. CEC had a negative correlation with FS, and the swelling performance of Na-Mnt was slightly better than that of Ca-Mnt.

Na-Mnt and Ca-Mnt with a water content of $0 \%$ to $70 \%$ have expanded by about 150\% (Figure 3). From a completely 


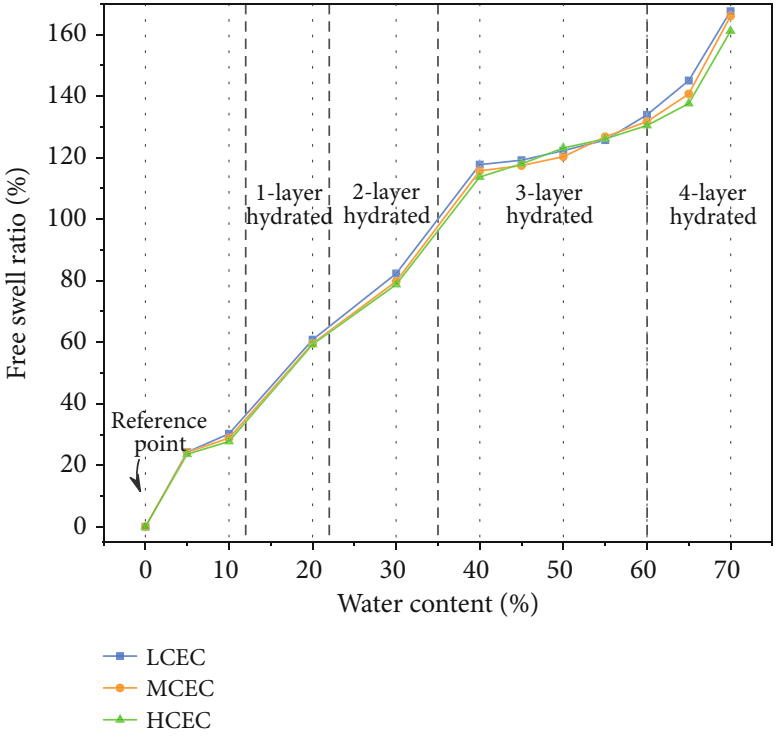

(a)

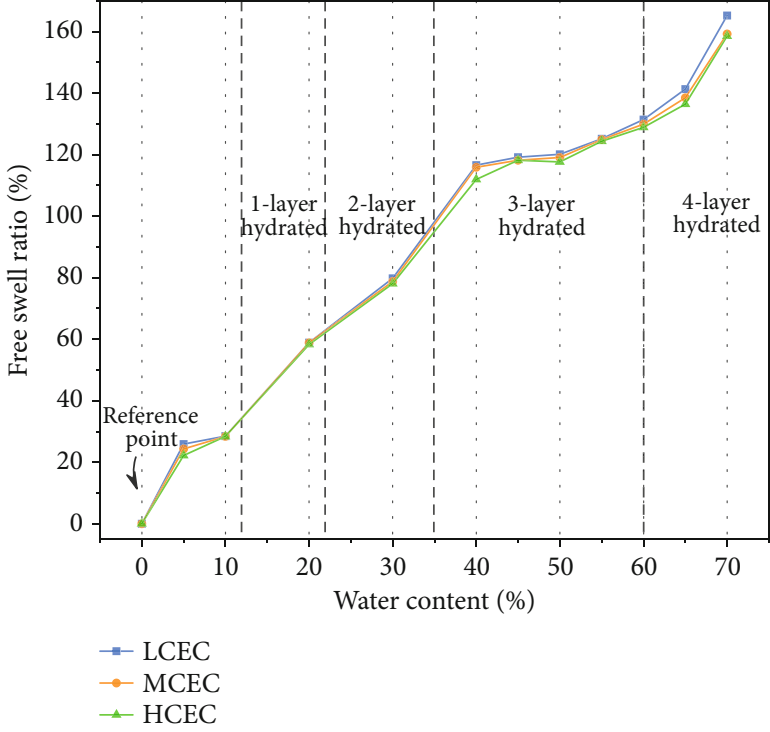

(b)

Figure 3: The relationship between free swelling ratio and water content: (a) Na-Mnt and (b) Ca-Mnt.

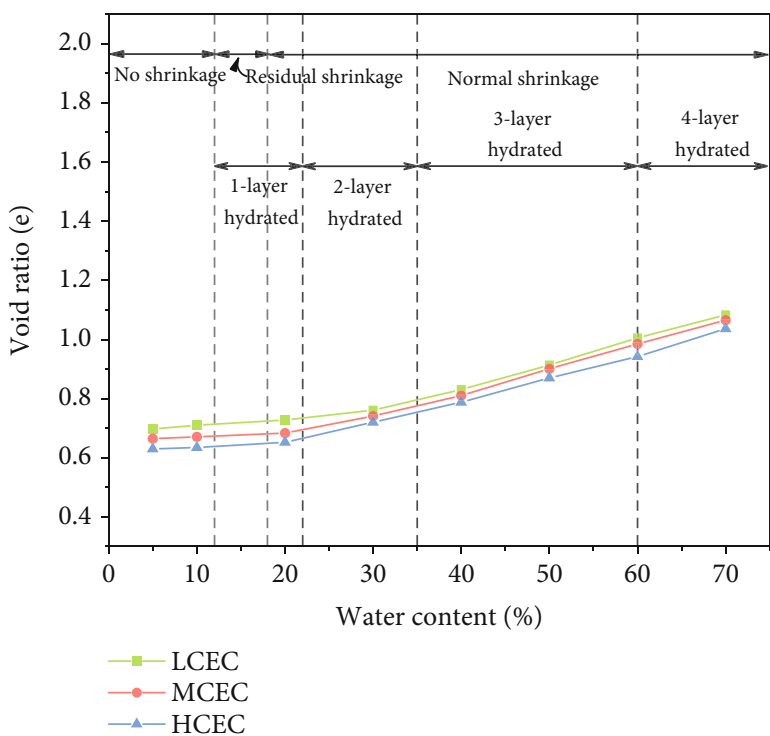

(a)

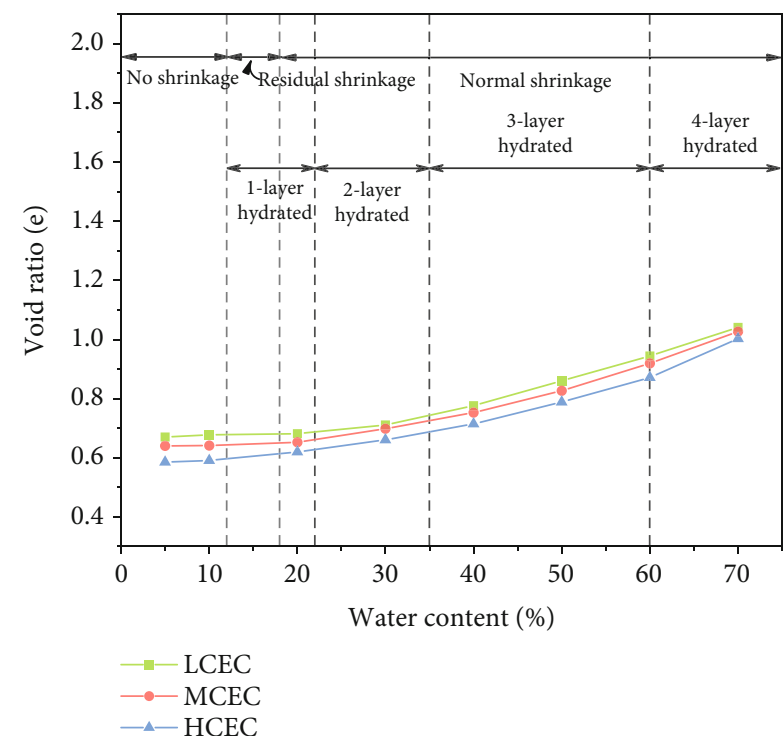

(b)

FIgure 4: Nanoscale shrinkage curve of Mnt: (a) Na-Mnt and (b) Ca-Mnt.

dry state to adsorb 16 to 32 water molecules (a water content of $5 \%$ to $10 \%$ ), the first layer of hydration was about to fill up. After entering the first hydrated state, FS of Mnt climbed rapidly, but the increasing trend slowed down when the second hydrated layer was formed. This may be closely connected with the aggregation of water molecules and the generation of hydrated layer. When the adsorption of the third hydrated layer was completed, FS at a water content of $40 \%$ reached $120 \%$, while the FS of the expansive soil measured by $\mathrm{Yu}$ et al. [38] on the macroscale is about $100 \%$. The difference between them may be due to the scale effect of the soil, but it largely indicated that Mnt is the main source of clay minerals for swelling of expansive soil. FS at the water content of $40 \%$ to $60 \%$ increased mildly, suggesting that the three-layer water molecules gradually transitioned to the four-layer, and a small swelling occurred when the four-layer hydration was established.

3.3. Shrinkage Curve of Montmorillonite. Figure 4 presents the shrinkage curve (the relationship between void ratio and water content) of nanoscale Na-Mnt and Ca-Mnt. As shown in Figures 4(a) and 4(b), with the desorption of water molecules, the crystal layer gradually shrunk in volume under external pressure, resulting in a continuous drop in 


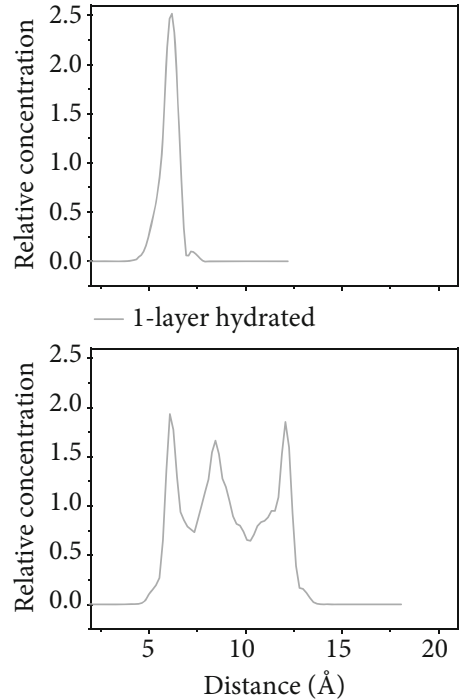

- 3-layer hydrated

(a)

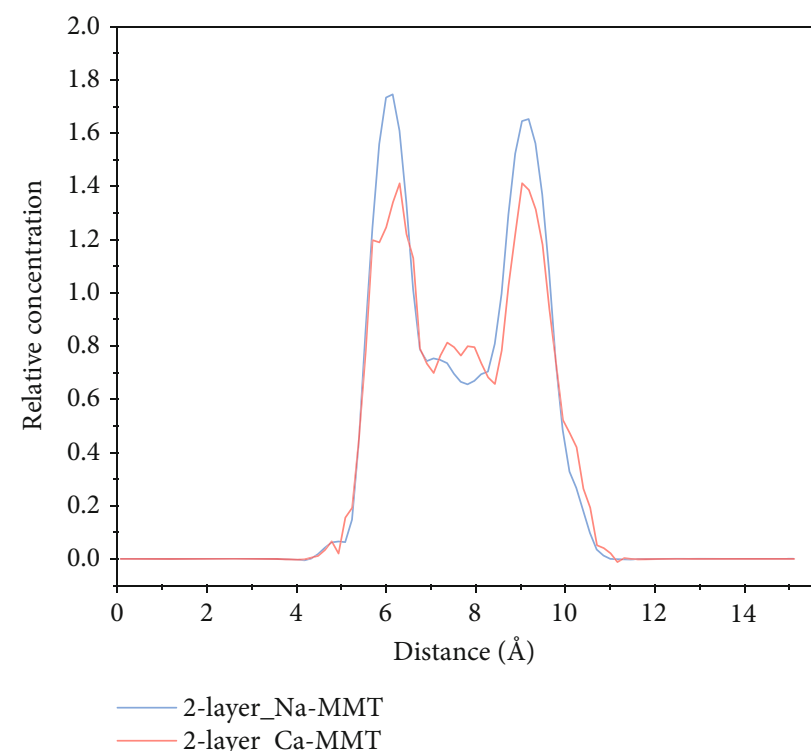

(c)

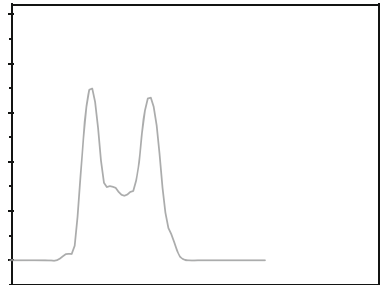

- 2-layer hydrated

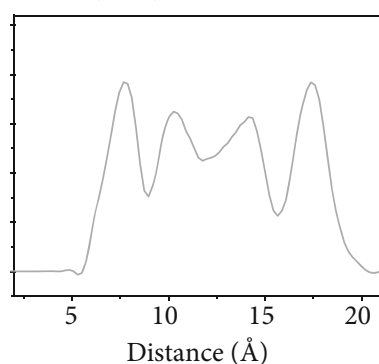

— 4-layer hydrated

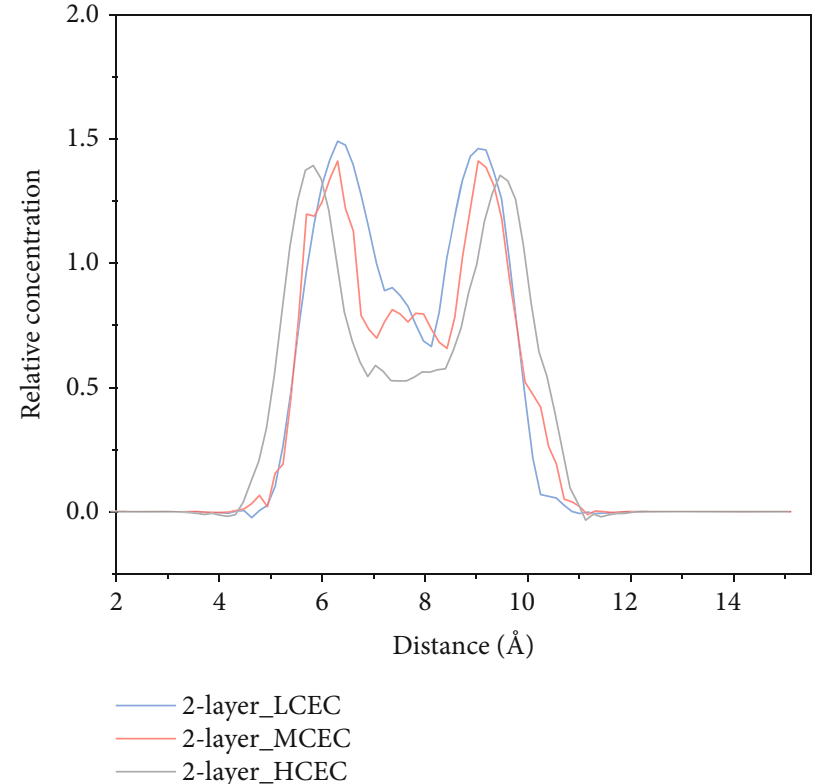

(b)

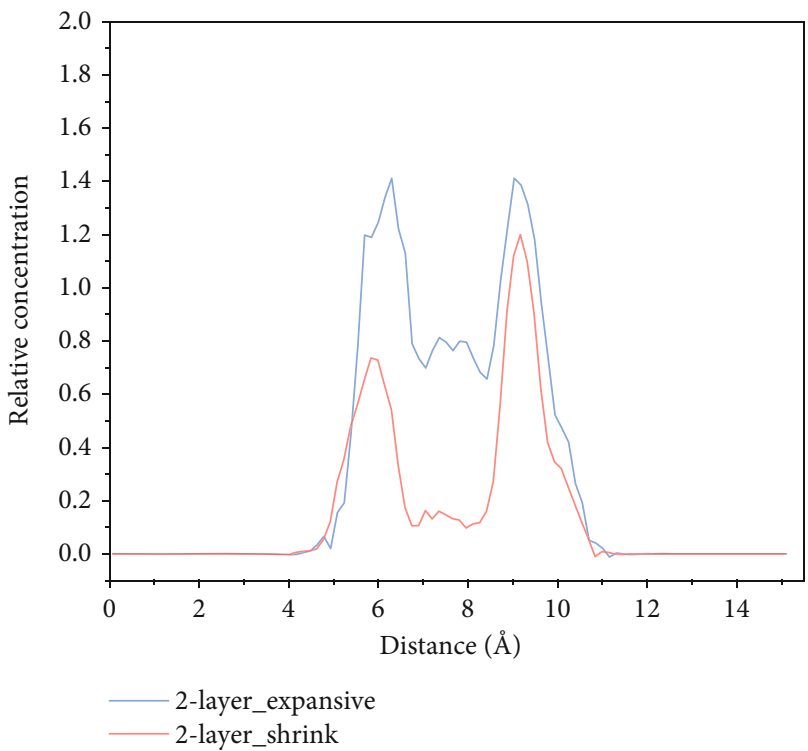

(d)

FIGURE 5: Distribution of water molecules along the $z$-axis: (a) different hydrated layers of Na-Mnt, (b) different CEC, (c) different types of interlayer cations, and (d) swelling and shrinking.

the void ratio of Mnt, and finally tended to stabilize. Compared with the expansive soil, the entire curve also roughly went through three stages [28]. The first was the linear development stage (water content $\geq 30 \%$ ). Water molecules began to desorb from $70 \%$ of the water content, and the reduced volume of the system was equal to the dehydrated volume. After the fourth hydration film disappeared, the volume was compressed under external pressure until the third hydration film was removed. The second was residual deformation (from 10\% to 30\%). The dry density of Mnt gradually went up as the water content went down, and the void ratio decreased at a slower rate. When the water content dropped to less than $10 \%$, in other words, when the system was in the stage of no shrinkage, the molecules of the first hydrated layer were closely combined with the interlayer cations. At this moment, the dry density of the mineral has reached $2.1 \mathrm{~g} / \mathrm{cm}^{3}$. The void ratio stayed constant at about 0.65 and no longer deformed. The main reason for the distinction between the shrinkage curves of expansive soil and nanosized Mnt should be attributed to the multiscale effect of the soil and the difference in mineral composition and structure.

The effects of types of interlayer cation and CEC on the shrinking behaviors of Mnt revealed that influenced by the swelling states, the void ratio of $\mathrm{Na}-\mathrm{Mnt}$ was slightly larger than that of Ca-Mnt under the same water content. The 


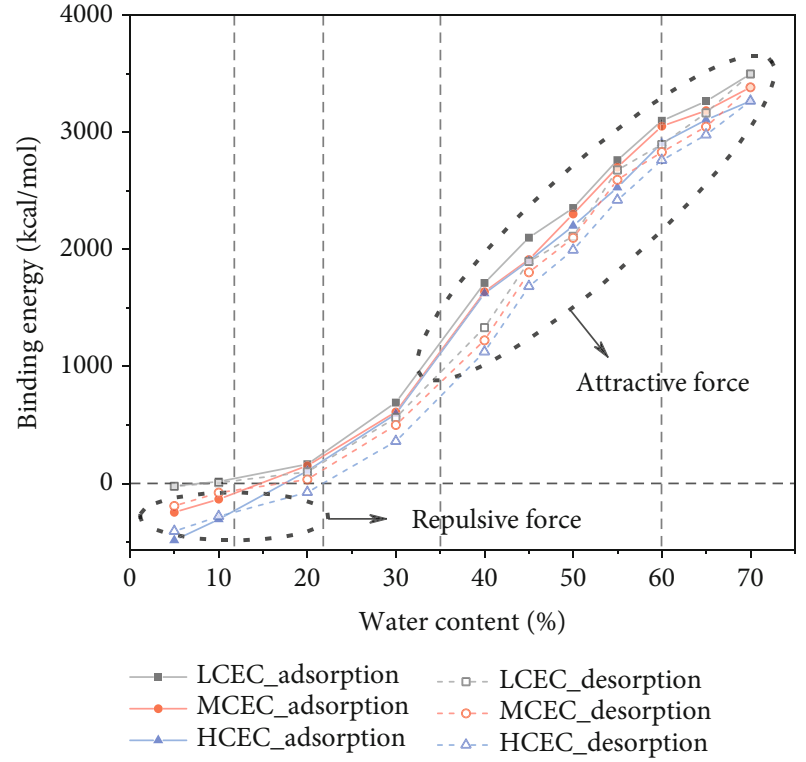

(a)

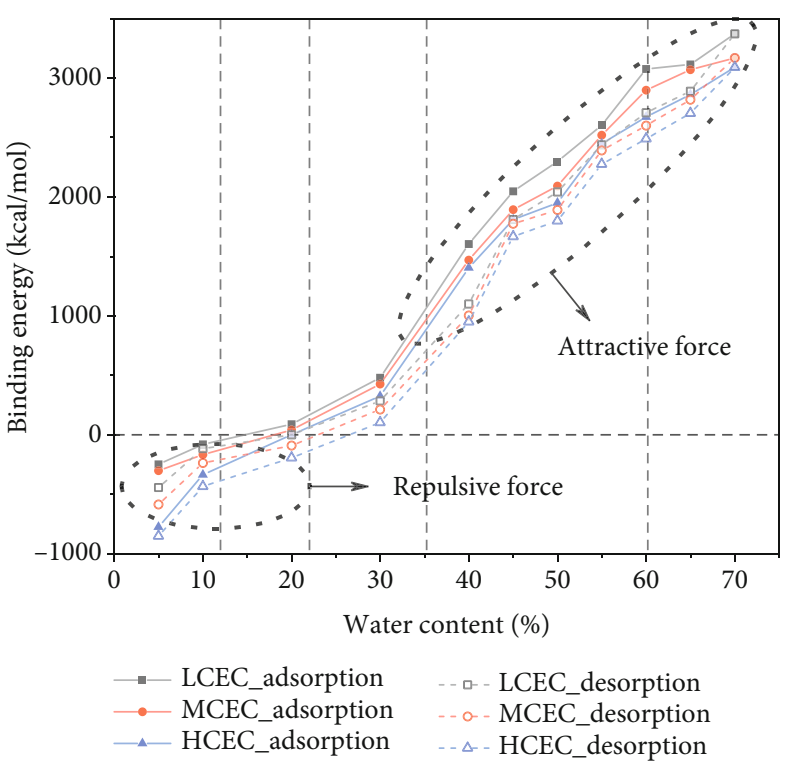

(b)

Figure 6: Changes in binding energy between solid and liquid molecules: (a) Na-Mnt and (b) Ca-Mnt.

higher the CEC, the smaller the void ratio, which is basically the same as the results of $d_{001}$-value in Figure 2 .

3.4. Swelling and Shrinking Mechanism. In order to explain the above-mentioned microscopic phenomena in depth, we will discuss the relative concentration of water molecules, the binding energy of solid-liquid molecules, and the number and length of hydrogen bonds.

3.4.1. Distribution of Water Molecules. The relative distribution of water molecules along the $z$-axis in the Na-Mnt model is presented in Figure 2(a). When Mnt adsorbed 32 water molecules, it appeared a peak along the $z$-axis, forming the first hydrated layer and concentrated in the center of the crystal layer. When water molecules were successively adsorbed and developed into a second hydrated layer, the main peak split into two symmetrical secondary peaks, and the peak value was reduced. Similarly, the third and fourth hydrated layers corresponded to 3 and 4 peaks, respectively. After the water molecules were arranged in layers, they became more dispersed. Fei [21] also obtained the related results. Figure 2(b) exhibits the distribution of water molecules between two layers of hydrated Ca-Mnt (with a water content of 20\%) under different CEC. The higher the CEC, the narrower the peak width, leading to the thinner the thickness of the hydration film and the worse the final swelling performance. It also explained the influence of CEC on $d_{001}$-value and FS. The swelling effects of Na-Mnt and Ca-Mnt also depended on the thickness of the hydration film in the process of absorbing water molecules. In Figure 5(c), the hydration film of Na-Mnt was slightly thicker than Ca-Mnt, so the swelling properties of the former had advantages over the latter. It is given that the ionic radius of $\mathrm{Na}$ is smaller than that of $\mathrm{Ca}$ and the hydrated ability of ions is inversely proportional to the ionic radius, which ensures the correctness of the simulation results. The water film between the layers of 2-layer hydrated Ca-Mnt became thinner in the shrinking state (Figure 5(d)). In comparison with the distribution of water molecules after swelling, the distance from the solid phase of the mineral was enlarged, promoting a certain agglomeration of water molecules. Hence, the interaction between the liquid and solid phases was weakened, and the crystal layer will shrink due to external pressure, generating hysteresis effects of swelling and shrinking.

3.4.2. Solid-Liquid Interaction. The force field, CLAYFF, only relies on the interaction of Coulomb electrostatic force and van der Waals force. The total potential energy of each component in (5) is mainly derived from the Coulomb electrostatic potential, van der Waals nonbonding potential energy, bond stretching, and angle bending of water molecule and hydroxyl bond [21].

Figures 6(a) and 6(b) demonstrate that the binding energy $\left(E_{\text {bind }}\right)$ between the solid phase of clay and the liquid phase of water molecules varied from -850 to $35000 \mathrm{kcal} / \mathrm{mol}$ in the range of $5 \%$ to $70 \%$ water content. When the water content of Mnt was nearly $20 \%$, there is no interaction between the solid and liquid phases. Based on Figures 5(b) and 5(c), the distance between the two layers of water molecules and the solid surface was about $10^{-10} \AA$, which is in the same order of magnitude as the equilibrium value in the change of molecular force with molecular distance [39]. As the water content increased, the distance between the outermost water molecules and the surface of the solid phase expanded (Figure 5(a)), causing a descent in the attractive and repulsive forces of solid-liquid molecules. However, the attractive force declined faster than the repulsive force, so the molecular force between the two phases in this stage appeared as attraction. Conversely, the reduction of water content made the distance between the solid-liquid molecules smaller, and the repulsive force will dominate. Combining the previous statement that the swelling of Mnt is controlled by the balance between the repulsive force caused by the 2:1 layer interaction and the attractive force 

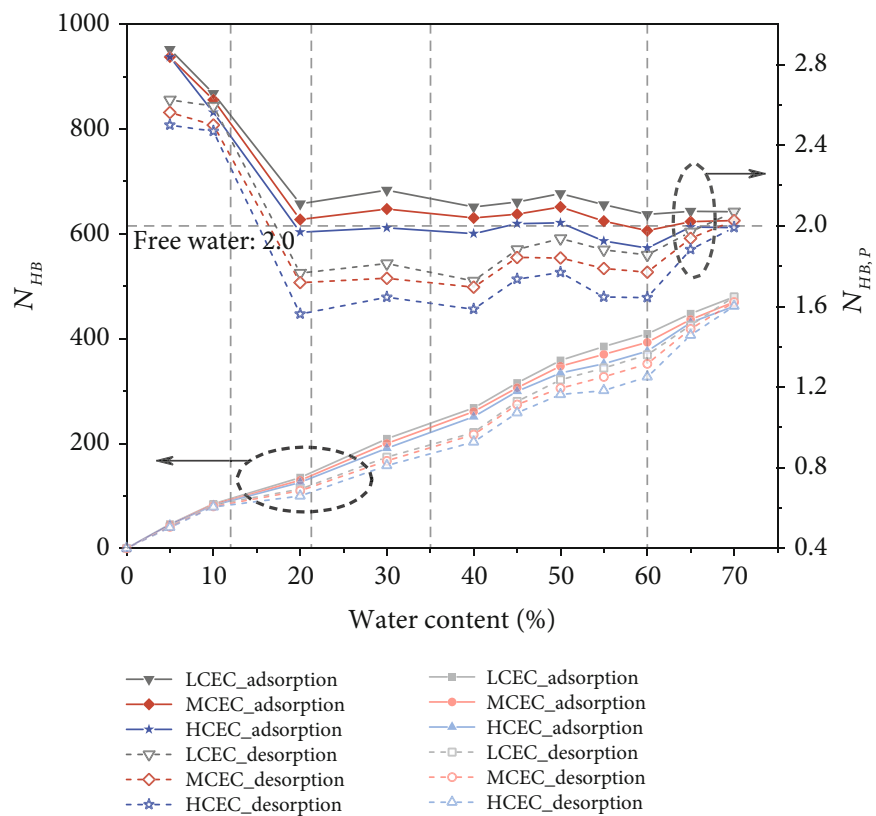

$$
\begin{aligned}
& - \text { LCEC_adsorption } \\
& - \text { MCEC_adsorption } \\
& -- \text { - HCEC_adsorption } \\
& -- \text { - LCEC_desorption } \\
& -- \text { - MCEC_desorption }
\end{aligned}
$$

(a)

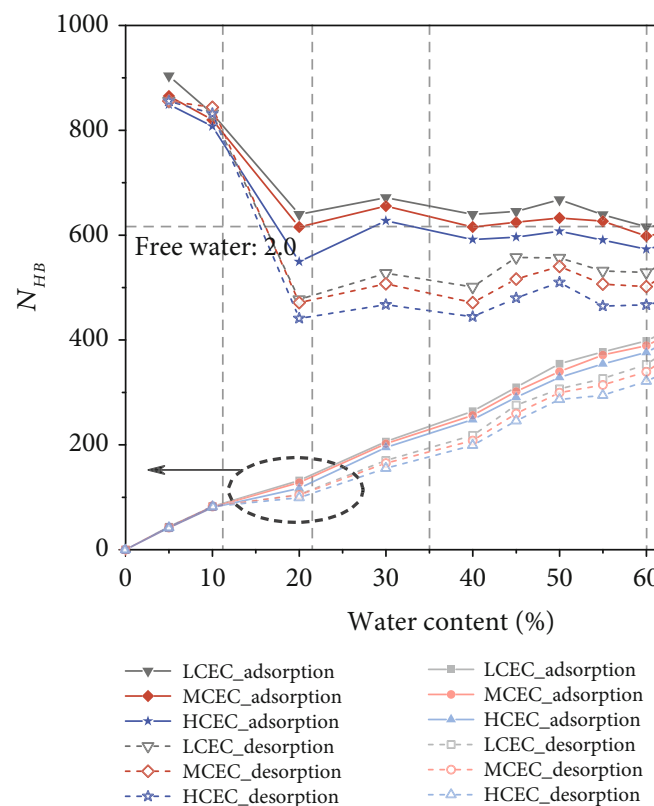

(b)

- MCEC_desorption

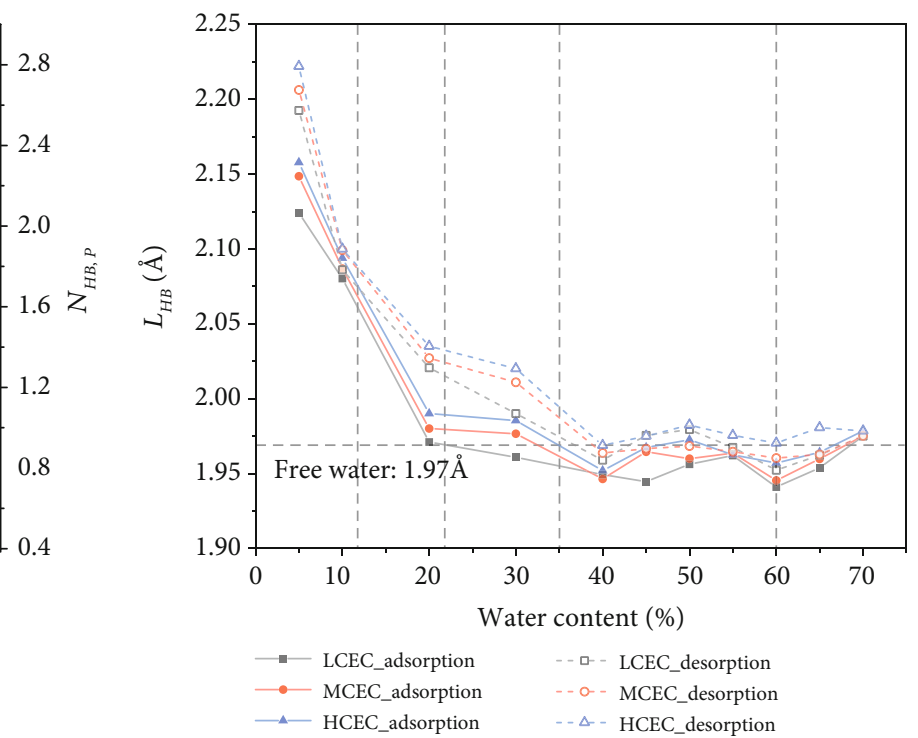

- LCEC adsorption

$\longrightarrow$ HCEC_adsorption $\quad \cdots \Delta$ HCEC_desorption

(c)

Figure 7: Continued. 


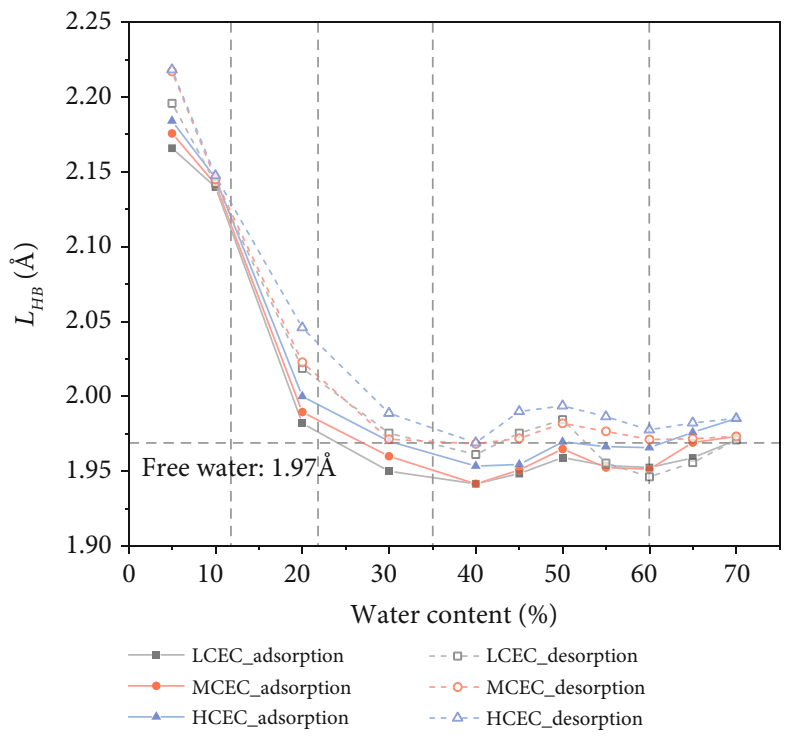

(d)

FIgure 7: Changes in the number and length of hydrogen bonds: (a) Na-Mnt, (b) Ca-Mnt, (c) Na-Mnt, and (d) Ca-Mnt.

between the cations of the hydrated layer and the negatively charged surface of the siloxane layer [40], the above findings have revealed that solid-liquid interaction in the process of swelling and shrinking is mainly manifested by attraction and repulsive force.

The binding energy between the solid and liquid phases was positively correlated with the water content, implying that the filling of water molecules induced the interaction of the two phases more intense. The desorption of water molecules resulted in the disappearance of the hydration film and the agglomeration of water molecules, and the interaction between the two phases also weakened. As presented in Figure 6, the changes in $E_{\text {bind }}$ are roughly similar to the trend in Figure 2. It can be inferred that the differences caused by factors such as water content, CEC, and types of cations could be mainly a reflection of the interaction between the two phases.

3.4.3. The Role of Hydrogen Bonds. As shown in Figures 7(a) and $7(b)$, the higher the water content of the mineral, the greater the number of hydrogen bonds in the system. The water content became lower, and the number of hydrogen bonds decreased. When the water content was within $20 \%$, $N_{\mathrm{HB}, \mathrm{p}}$ and $L_{\mathrm{HB}}$ dropped the fastest. When the water content exceeded $20 \%$, influenced by the hydrated state of Mnt, the fluctuation of $N_{\mathrm{HB}, \mathrm{p}}$ and $L_{\mathrm{HB}}$ gradually reduced, which is slightly larger than the average $N_{\mathrm{HB}, \mathrm{p}}$ and $L_{\mathrm{HB}}$ in free water. It can be speculated that in the process of swelling, in addition to hydrogen bonds between water molecules, bridging oxygen atoms on the surface of the wafer could be also generated until the occupancy of bridging oxygen atoms is completely utilized in the range of water content from $0 \%$ to $20 \%$. After the water molecules reached a certain number (water content $>20 \%$ ), the newly inhaled water molecules expanded the interlayer spacing and formed hydrogen bonds with the bridging oxygen atoms on the surface, but the over- all increase in hydrogen bonds mainly came from the hydrogen bonds between water molecules. With the continuous adsorption of water molecules, the average $N_{\mathrm{HB}, \mathrm{p}}$ and $L_{\mathrm{HB}}$ between the layers were close to the stable value of free water (2.0 and $1.97 \AA$ ) [41].

For the shrinking of Mnt, the successive desorption of water molecules induced the rupture of the hydrogen bonds between the outermost hydration film and the bridging oxygen atoms of the wafer, as well as between the water molecules. Then, the distance between the new outermost water molecules and the surface of the crystal layer enlarged to weaken the interaction, so the volume shrunk because of external pressure and promoted new hydrogen bonds with the bridging oxygen atoms. As the water molecules further desorbed, the hydrogen bonds in the system continued to break. Until it is in the 1-layer hydrated state (the water content was less than $20 \%$ ), the hydrogen bonds between the water molecules and between the water molecules and the bridging oxygen atoms were gradually and completely destroyed.

The dissimilarity in the number of hydrogen bonds between water molecules in this paper and free water may stem from the hydration of interlayer cations, which locally destroyed the tetrahedral coordination structure of water molecules. The hydrogen bonds formed between water molecules, and bridging oxygen caused the average $N_{\mathrm{HB}, \mathrm{p}}$ and $L_{\mathrm{HB}}$ to be different from free water during swelling and shrinking of Mnt. Equivalently, the distinction in the properties of hydrogen bonds with different CEC, state of swelling and shrinking, and types of cations can also be attributed to the above reasons. Since the longer the hydrogen bond, the weaker the hydrogen bond [42], namely, the smaller the interaction between molecules. Thus Figures 7(c) and 7(d) illustrate the disparity in the swelling and shrinking of different CEC and interlayer cations from another view. Judging from Figures 2 and 6 , the changes in $N_{\mathrm{HB}}, d_{001}$-value, and $E_{\text {bind }}$ with water 
content are almost similar, implying that the swelling and shrinking effects of Mnt may be mainly due to the results of molecular interaction, and this interaction is closely related to hydrogen bonding.

\section{Conclusions}

In the present study, the Monte Carlo and molecular dynamics methods were used to carry out a series of studies on the influence of CEC, water content, and types of interlayer cation. The phenomena of nanosized Mnt were discussed through the changes of basal spacing, free swelling ratio, and void ratio. Compared with previous simulation results and experimental data, the reaction mechanism was explained in terms of the relative distribution of water molecules, solid-liquid interaction, and hydrogen bonds. The key findings can be summarized as follows:

(1) Water content, types of interlayer cations, and CEC have a certain influence on the basal spacing of Mnt. The higher the water content, the larger the basal spacing. As the CEC decreased, the basal spacing increased. Furthermore, Na-Mnt has a weak swelling advantage over Ca-Mnt. When the water content was in the range of $30 \% \sim 50 \%$, the swelling and shrinking of Mnt had apparent hysteresis phenomena

(2) Affected by the hydrated state of Mnt, the changes of the free swelling ratio were basically consistent with the basal spacing in the swelling stage. When the water content was $70 \%$, the free swelling ratio reached nearly $150 \%$. By comparison with the expansive soil, the nanoscale shrinkage curves of Na-Mnt and Ca-Mnt also experienced three stages of linear normal shrinkage, residual shrinkage, and no shrinkage

(3) The differences between the swelling and shrinking phenomena of Mnt with different water content, interlayer cation, and CEC were closely related to the distribution of water molecules. If the water content goes up, the number of hydrated layers will go down. With the rise of CEC, the thickness of the hydration film declined. The thickness of the hydration film in the shrinking state became thinner than that in the swelling state, and the agglomeration between water molecules was enhanced. The binding energy of the solid and liquid phases was directly proportional to the water content. The water content around $20 \%$ was the critical point of the attractive and repulsive forces in the intermolecular forces. The difference in swelling and shrinking caused by various factors could be mainly due to the molecular interaction between the two phases

(4) The number of hydrogen bonds was roughly similar to the changes in binding energy and basal spacing. The distinction between the swelling and shrinking of $\mathrm{Mt}$ lies in the adsorption and desorption of water molecules, and it is essentially reflected in the formation and breaking of hydrogen bonds. The hydration of interlayer cations and the hydrogen bonds between water molecules and bridging oxygen atoms on the surface of the wafer may make the number and length of hydrogen bonds slightly different from those of free water, which explains the influences of above variables

\section{Data Availability}

The data used to support the findings of this study are available from the corresponding author upon request.

\section{Conflicts of Interest}

The authors declare that they have no known competing financial interests or personal relationships that could have appeared to influence the work reported in this paper.

\section{Acknowledgments}

This research was financially supported by the National Natural Science Foundation of China (Grant Nos. 42172308 and 42077270).

\section{References}

[1] S. X. Chen, Study on Engineering Behaviors of Expansive Soils and Its Treatment Measures, Huazhong University of Science and Technology, 2006.

[2] D. E. Jones and W. G. Holtz, "Expansive soils-the hidden disaster," Civil Engineering, vol. 43, no. 8, pp. 49-51, 1973.

[3] K. V. Ramana, "Expansive soils: problems and practice in foundation and pavement engineering," Engineering Geology, vol. 35, no. 1-2, pp. 136-138, 1993.

[4] Y. Z. Wang, Theoretical and Experimental Study on Scale Effects of Soil, South China University of Technology, 2014.

[5] D. L. Feng, Y. G. Fang, and M. X. Hou, "Theoretical and experimental studies of particle size effect of mechanical properties of soil," Rock and Soil Mechanics, vol. 36, no. 6, pp. 209-214, 2015.

[6] Y. Wang, H. Meng, and D. Long, "Experimental investigation of fatigue crack propagation in interbedded marble under multilevel cyclic uniaxial compressive loads," Fatigue \& Fracture of Engineering Materials \& Structures, vol. 44, no. 4, pp. 933-951, 2021.

[7] Y. Wang, Y. F. Yi, C. H. Li, and J. Q. Han, "Anisotropic fracture and energy characteristics of a Tibet marble exposed to multi-level constant-amplitude (MLCA) cyclic loads: a labscale testing," Engineering Fracture Mechanics, vol. 244, article 107550, 2021.

[8] W. Sun and D. Sun, "Coupled modelling of hydro-mechanical behaviour of unsaturated compacted expansive soils," International Journal for Numerical and Analytical Methods in Geomechanics, vol. 36, no. 8, pp. 1002-1022, 2012.

[9] H. R. Ahmed and S. N. Abduljauwad, "Nano-level constitutive model for expansive clays," Géotechnique, vol. 67, no. 3, pp. 187-207, 2017.

[10] Y. Wang, B. Zhang, B. Li, and C. H. Li, "A strain-based fatigue damage model for naturally fractured marble subjected to 
freeze-thaw and uniaxial cyclic loads," International Journal of Damage Mechanics, 2021.

[11] M. Eghbalian, M. Pouragha, and R. Wan, "Micromechanical approach to swelling behavior of capillary-porous media with coupled physics," International Journal for Numerical \& Analytical Methods in Geomechanics, vol. 43, no. 1, pp. 353-380, 2019.

[12] E. S. Boek, P. V. Coveney, and N. T. Skipper, "Monte Carlo molecular modeling studies of hydrated Li-, Na-, and K-smectites: understanding the role of potassium as a clay swelling inhibitor," Journal of the American Chemical Society, vol. 117, no. 50, pp. 12608-12617, 1995.

[13] V. Marry, P. Turq, T. Cartailler, and D. Levesque, "Microscopic simulation of structure and dynamics of water and counterions in a monohydrated montmorillonite," The Journal of Chemical Physics, vol. 117, no. 7, pp. 3454-3463, 2002.

[14] F.-R. C. Chang, N. T. Skipper, and G. Sposito, "Computer simulation of interlayer molecular structure in sodium montmorillonite hydrates," Langmuir, vol. 11, no. 7, pp. 2734-2741, 1995.

[15] J. Wang and F. Zeng, "Molecular dynamics simulations for hydration swelling and interlayer structure of $\mathrm{Na}$-montmorillonite," Journal of The Chinese Ceramic Society, vol. 33, no. 8, pp. 996-1001, 2005.

[16] D. R. Katti, K. B. Thapa, and K. S. Katti, "The role of fluid polarity in the swelling of sodium-montmorillonite clay: a molecular dynamics and Fourier transform infrared spectroscopy study," Journal of Rock Mechanics and Geotechnical Engineering, vol. 10, no. 6, pp. 1133-1144, 2018.

[17] S. N. Abduljauwad and H. U. R. Ahmed, "Use of nano-level constitutive model to predict the volume change behavior of the treated expansive clays," in IFCEE 2018, pp. 143-153, Orlando, FL, 2018.

[18] B. Li, The Effect of Temperature on the Interlayerstructure of $\mathrm{Na}$-, Cs-Montmorillonite Using Molecular Simulation, Taiyuan University of Technology, 2013.

[19] M. H. Fu, "Changes in the properties of a montmorillonitewater system during the adsorption and desorption of water: hysteresis1," Clays \& Clay Minerals, vol. 38, no. 5, pp. 485492, 1990.

[20] I. Berend, Les Mécanismes d'Hydratation de Montmorillonites Homoioniques pour des Pressions Relatives Inferieures à 0.95, Vandoeuvre-les-Nancy, INPL, 1991.

[21] K. L. Fei, Multi-Scale Study on the Basic Mechanisms of High Stress Mechanical Properties for Saturated Montmorillonite, China University of Mining and technology, Xuzhou, 2013.

[22] M. Chavez-Paez, K. V. Workum, and L. D. Pablo, "Monte Carlo simulations of Wyoming sodium montmorillonite hydrates," Journal of Chemical Physics, vol. 114, no. 3, pp. 1405-1413, 2001.

[23] Y. Zheng, A. Zaoui, and I. Shahrour, "A theoretical study of swelling and shrinking of hydrated Wyoming montmorillonite," Applied Clay Science, vol. 51, no. 1-2, pp. 177-181, 2011.

[24] N. T. Skipper, "Monte Carlo simulation of interlayer molecular structure in swelling clay minerals. 1. Methodology," Clays \& Clay Minerals, vol. 43, no. 3, pp. 285-293, 1995.

[25] T. R. Underwood and I. C. Bourg, "Large-scale molecular dynamics simulation of the dehydration of a suspension of smectite clay nanoparticles," The Journal of Physical Chemistry C, vol. 124, no. 6, pp. 3702-3714, 2020.

[26] W. Loewenstein, "The distribution of aluminum in the tetrahedra of silicates and aluminates," American Mineralogist, vol. 39, no. 1, pp. 92-97, 1954.
[27] V. Romanov and E. M. Myshakin, "Experimental studies: clay swelling," in Greenhouse Gases and Clay Minerals. Green Energy and Technology, V. Romanov, Ed., Springer, Cham, 2018.

[28] C. S. Tang, "Study on desiccation cracking behaviour of expansive soil," Journal of Engineering Geology, vol. 20, no. 5, pp. 663-673, 2012.

[29] R. T. Cygan, J. J. Liang, and A. G. Kalinichev, "Molecular models of hydroxide, oxyhydroxide, and clay phases and the development of a general force field," The Journal of Physical Chemistry B, vol. 108, no. 4, pp. 1255-1266, 2004.

[30] W. N. Zhang, H. X. Hu, and X. C. Li, "Changes in micromechanical properties of Na-montmorillonite caused by $\mathrm{CO}_{2} / \mathrm{H}_{2} \mathrm{O}$ sorption," Computational Materials Science, vol. 129, pp. 178-183, 2017.

[31] R. Martos-Villa, S. Guggenheim, and M. P. Mata, "Interaction of methane hydrate complexes with smectites: experimental results compared to molecular models," American Mineralogist, vol. 99, pp. 401-414, 2014.

[32] W. Dai, Z. H. Shui, C. H. Shen, and K. Li, "Monte Carlo simulation on adsorption characteristics of water in kaolin," Journal of the Chinese Ceramic Society, vol. 40, no. 1, pp. 149-153, 2012.

[33] H. D. Whitley and D. E. Smith, "Free energy, energy, and entropy of swelling in Cs-, Na-, and Sr-montmorillonite clays," Journal of Chemical Physics, vol. 120, no. 11, pp. 5387-5395, 2004.

[34] X. L. Fu, X. Z. Fan, and X. H. Ju, "Molecular dynamic simulations on the interaction between an HTPE polymer and energetic plasticizers in a solid propellant," RSC Advances, vol. 5, 2015.

[35] G. Gilli and P. Gilli, "Towards an unified hydrogen-bond theory," Journal of Molecular Structure, vol. 552, no. 1-3, pp. 1-15, 2000.

[36] Y. Zheng, A. Zaoui, and I. Shahrour, "Evolution of the interlayer space of hydrated montmorillonite as a function of temperature," American Mineralogist, vol. 95, no. 10, pp. 14931499, 2010.

[37] H. Peron, T. Hueckel, L. Laloui, and L. B. Hu, "Fundamentals of desiccation cracking of fine-grained soils: experimental characterisation and mechanisms identification," Canadian Geotechnical Journal, vol. 46, no. 10, pp. 1177-1201, 2009.

[38] S. Yu, S. X. Chen, and X. C. Xu, "Testing study on relative free swelling ratio for expansive soil," Chinese Journal of Rock Mechanics and Engineering, vol. 25, pp. 3330-3335, 2006.

[39] E. R. Lippincott and R. Schroeder, "General relation between potential energy and internuclear distance for diatomic and polyatomic molecules. I," The Journal of Chemical Physics, vol. 23, no. 6, pp. 1131-1141, 1955.

[40] E. Ferrage, B. Lanson, and B. A. Sakharov, "Investigation of smectite hydration properties by modeling experimental Xray diffraction patterns: part I. montmorillonite hydration properties," American Mineralogist, vol. 90, no. 8-9, pp. 1358-1374, 2005.

[41] M. Hakala and S. Manninen, "Correlation of hydrogen bond lengths and angles in liquid water based on Compton scattering," The Journal of Chemical Physics, vol. 125, no. 8, article 084504, 2006.

[42] E. R. Johnson, S. Keinan, and P. Mori-Sanchez, "Revealing noncovalent interactions," Journal of the American Chemical Societ, vol. 132, no. 18, pp. 6498-6506, 2010. 